\title{
Analysis of Nutrients and Phytochemicals content in Corn Silk(Zea. Mays)
}

\author{
${\text { Bhuvaneshwari K. }{ }^{1} \text {, M.sc FSMD, Dr. P. L. Sridevi Sivakami }}^{2}$ \\ ${ }^{1}$ Research Scholar, Department of Food Service Management and Dietetics, \\ Avinashilangam Institute for Home Science and Higher Education for Women, Coimbatore- 43 \\ ${ }^{2}$ Associate Professor, Department of Food Service Management and Dietetics, \\ Avinashilangam Institute for Home Science and Higher Education for Women, Coimbatore- 43.
}

\begin{abstract}
When environmental conditions are degraded such that the range of tolerance is exceeded, there will be a significant impact on human health. Free radicals were well documented for playing a dual role as both deleterious and beneficial species. In lower or moderate concentration free radicals are involved in normal physiological functions but excess production leads to oxidative stress. The plant sources are rich in antioxidants. Dietary plants contain variable chemical families and enormous amount of antioxidants. The plant based foods introduce significantly more antioxidant into human diet then non-plant foods. Corn silk will be used to produce novel natural antioxidants as well as flavouring agents in various products. Organic acids like formic acids, lactic acid, succinic acid, palmitic acid, steric acid, oleic acid and linolic acid are presented in corn silk. The present study shows the nutrients present in the corn silk. Corn silk contains higher amount of fibre (6g) and less in fat $(0.36 \mathrm{~g})$. Total antioxidant activity and total phenolic content of dried corn silk was analysed. Microwave dried corn silk contains high amount of total antioxidant activity.
\end{abstract}

Keywords: Antioxidant, corn silk, nutrients, phenolic content

\section{Introduction}

Antioxidants are free radical scavengers which provide protection to living organism from damage caused by environmental impacts which results in uncontrolled protection of reactive oxygen species and DNA strand breaking. Plants have been used for centuries as remedy for human diseases because they contain many therapeutic values and it possess free radical scavenging activities (Bentley and Trimen, 2007). Globally there is much interest in knowing about edible plants with antioxidants and phytonutrients which might decrease the burden of chronic illness as well as nutrigenumic. Corn silk is scientifically referred as Maydis stigma, they are soft, fibre like growth which accompanies the ear of the corn. The length of corn silk thread was from 10-20 cm long and of light green or yellowish brown in colour (Rosli et al., 2008).

Corn silk is rich in antioxidants such as saponins, allantoin, sterols, especially beta sitosterol and stigmasterol, alkaloid, polyphenols, mucilage, vitamin $\mathrm{K}$, vitamin $\mathrm{C}$, anthocyanins, plant acid and tannins. Corn silk consists of various chemical nutrient compound including proteins, vitamins, alkaloids, tannins, mineral salts, carbohydrates, steroids and flavonoids as well as volatile chemicals (Ren and Ding, 2006). The glycoproteins from corn silk inhibit the IgE antibody formation and enhance $\operatorname{IgG}$ and $\operatorname{IgM}$ formation (Khare, 2007).

Corn silk has a significant pharmacological activity with a broad development prospects including immune function regulations, anti tumour, antibacterial, anti oxidation, anti diuretic (Sharma et al.,2009), urinary tract stone formation, lowering blood glucose, blood lipids and blood pressure levels (Lil and Yan, 2009). Maize has sufficient evidence to support the traditional use for urinary problems, cooling and high cholesterol (Lans, 2006). Corn silk could be used to produce novel natural antioxidants as well as flavouring agent in various products (El-Ghorab, et al., 2007). In Greece the corn silk are used as decoction to treat urinary bladder diseases, in Philippines the plant is considered as diuretic, anodyne and demulant. The liquid extract of corn silk is sold in market as a remedy for irritable condition of bladder (Bentley and Trimen, 2007). The present study was undertaken to analyse the nutrients of total antioxidant activity and phenolic content present in corn silk.

\section{Materials and Methods}

\subsection{Collection of Plant Materials}

The corn silk threads are normally discarded during the processing of corn. Studies show that corn silk contains micronutrients and minerals. Discarded fresh corn silk was obtained during the month of December 2011 to January 2012. Nearly one kilo gram of corn silk was obtained from the waste.

\subsection{Drying the Collected Sample Materials}

Drying is one of the man's oldest method of food preservation, copied from nature and cheapest method. Water is present in all foods in relatively large quantities, when the water is removed both the weight and the volume of food products are reduced. Dried and dehydrated foods are more concentrated than any other preserved form of food stuffs. In drying methods, food losses its moisture content, results in increasing concentration of nutrients in the remaining mass. Collected sample of corn silk was cleaned, weighed and separated into three groups and grouped as sample 1, 2 and 3. Sample 1 was dried in microwave for $\mathbf{7 - 8}$ min, sample 2 was kept under sundry for 7 hours and sample 3 was kept under shadow dry for 5 days.

The main purpose of drying of corn silk was done to increase the shelf life. To liberate antioxidant and obtain 


\section{International Journal of Science and Research (IJSR) \\ ISSN (Online): 2319-7064}

Index Copernicus Value (2015): 78.96 | Impact Factor (2015): 6.391

natural antioxidants from plant, high temperature is one of the effective methods.

\subsection{Analysis of Major Nutrients Present in Corn Silk}

Corn silk is rich in B complex vitamins, vitamin A (Beta carotene), vitamin $\mathrm{k}$ and minerals like sodium and potassium. The silk grown in the corn plant will also contain some amount of nutrients. So the collected plant material (Fresh corn silk) was analysed for its major nutrients like carbohydrates, proteins, fats, crude fibre and moisture (figure-1).

\subsection{Assay of Total Antioxidant Activity and Phenolic Content of Corn Silk}

Free radicals are associated with various physiological and pathological events such as inflammation, aging, mutagenicity and carcinogenicity. The free radical refers to any chemical species possessing one or more unpaired electrons. Antioxidants are free radicals scavengers which provide protection to free radicals.

Traditionally corn silk is consider as a medicinal plants and it is treated for many kidney disorders, so to find the total antioxidant activity, phenolic content, dried corn silk (sample1, sample 2, sample 3) was analysed. The methods used to analyse antioxidant activity was FRAP (Ferric Reducing Antioxidant Power) and phenoilc content was analysed by Folin-ciocalteau method.

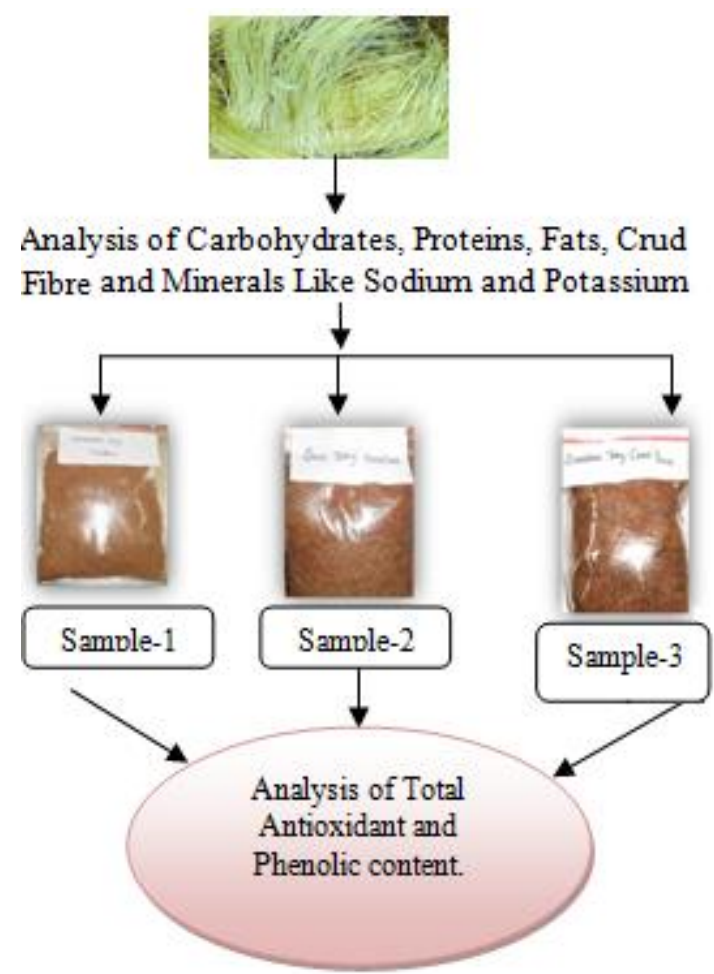

Figure 1: Flow chart of preparation of corn silk

\section{Results and Discussion}

\subsection{Hidden Qualities of Corn Silk}

Nutrients present in the food come under hidden quality characteristic of food (Raj et al., 2011). Corn silk grown in the cob contains flavonoids, alkaloids, phenols and steroids, so the fresh corn silk was analysed in the laboratory were shown in the Table I. Moisture content was high in corn silk (i.e) 57.50 per cent, due to its soft and humid nature. The amount of carbohydrates and proteins present in the corn silk was $27.8 \mathrm{~g}$ and $5.78 \mathrm{~g}$ respectively. Only $0.36 \mathrm{~g}$ of fats was present in the silk. So, corn silk can be used in the treatment for liver diseases. The amount of crude fibre present in the corn silk was six grams due to the fibrous structure, similarly corn silk is also rich in minerals like sodium $(720.27 \mathrm{mg})$ and potassium $(1079.80 \mathrm{mg})$, because corn silk absorbs more amount of minerals from the soil.

Table 1: Nutrients Components of Fresh Corn Silk

\begin{tabular}{|c|c|c|}
\hline Methods of Drying & $\begin{array}{c}\text { Total antioxidant } \\
\text { activity }(\mathrm{mg} \backslash \mathrm{g})\end{array}$ & $\begin{array}{c}\text { Total phenols } \\
(\mathrm{mg} \backslash \mathrm{g})\end{array}$ \\
\hline Microwave & 9.98 & 1.20 \\
\hline Sun & 5.61 & 0.85 \\
\hline Shadow & 7.22 & 1.33 \\
\hline
\end{tabular}

3.2 Total antioxidant activity and phenolic content in dried corn silk

Enhancement and prolongation of human life are the primary or underlying goals of the entire human. Antioxidants present in the food not only help in preserving the foods but also helps in reducing fat oxidation, which produce free radicals (Schmidl and Labuza, 2009). Some foods contain non nutrient such as antioxidants, most of which are phenolic compounds or polyphenols which are important to human health because of their antioxidant action (Langseth 2009).

Corn silk can be used either as fresh or dry. The keeping quality of the corn silk was high when it was dried. Various drying methods (microwave, sun dry and shadow dry) were adapted to dry the fresh corn silk and analysed antioxidant activity and phenolic content is depicted in the Table II and shown in the Fig-2

Table 2: Total Antioxidant activity and phenolic content of dried corn silk

\begin{tabular}{|l|c|}
\hline Nutrients & Fresh corn silk \\
\hline Moisture $(\mathrm{g})$ & 57.50 \\
\hline Carbohydrates $\mathrm{g})$ & 27.80 \\
\hline Proteins $(\mathrm{g})$ & 5.78 \\
\hline Fats $(\mathrm{g})$ & 0.36 \\
\hline Crude Fibre $(\mathrm{g})$ & 6.00 \\
\hline Sodium $(\mathrm{mg})$ & 720.27 \\
\hline Potassium $(\mathrm{mg})$ & 1079.08 \\
\hline
\end{tabular}




\section{International Journal of Science and Research (IJSR) \\ ISSN (Online): 2319-7064}

Index Copernicus Value (2015): 78.96 | Impact Factor (2015): 6.391

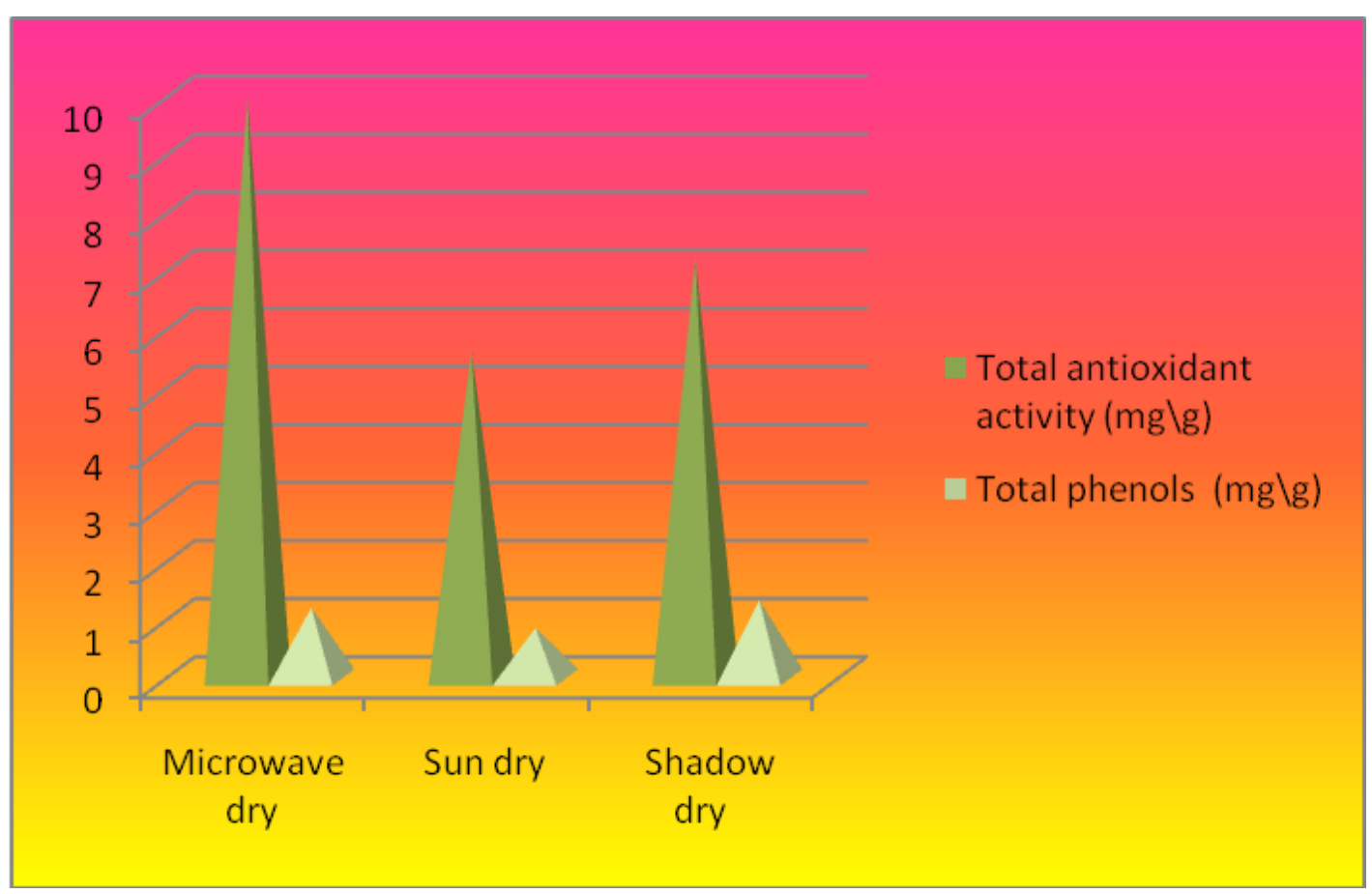

Figure 2: Total Antioxidant activity of dried corn silk

In sun drying method, food losses much of their vitamins and a part of their minerals, longer the period of drying greater will be the losses (Bhutani, 2006). Corn silk dried under sun had less total antioxidant activity of $5.61 \mathrm{mg}$ and also less in phenolic content $(0.85 \mathrm{mg})$ due to its longer period of exposure (seven hours) under sun dry method.

During application of heat, certain vitamins may lose to some extent. Mechanically dried products possess sufficient nutritive properties because the nutrients become concentrated after eliminating the maximum possible water and so it does not destroy the food value. Thus, the total antioxidant activity in microwave dried corn silk was found to be $9.98 \mathrm{mg}$, which was high when compared to other methods of drying. Phenols are the volatile compounds, when these compounds are exposed under heat, the losses will be high. Phenolic content of shadow dried corn silk was very high of about $1.33 \mathrm{mg}$ when compared to microwave dried corn silk $(1.20 \mathrm{mg})$ and sun dried corn silk $(0.85 \mathrm{mg})$.

\section{Summary and Conclusion}

Corn silk is a medicinal plant that grows upto 4-6 inches in the cob of corn plant. It contains many therapeutic and nutritional values. The present study shows that corn silk is rich in minerals like sodium and potassium. It possess high amount of antioxidant and phenolic content, so it can be used in the treatment of several ailments. Corn silk is a natural herb that can be taken for a longer period of time.

\section{References}

[1] Bentley, R. and H. Trimen, 2007. Medicinal Plants. Vol. 2. Ajay Book Science, New Delhi, India, pp: 13241327.

[2] Bhutani, R.C., 2006. Fruit and Vegetable Preservation . Biotech Books, New Delhi, ISBN-10: 81-7622-0809,pp:231-235.
[3] Ren, S. and X. Ding, 2006. Determination of organic acid in cornsilk with GC-MS. J.Wuxi Univ. Light Indus., 2006: 1386-1399.

[4] El-Ghorab, A., K.F. El-Massry and T. Shibamoto, 2007. Chemical composition of the volatile extract and antioxidant activities of the volatile and non volatile extracts of egyptian corn silk $(<\mathrm{i}>$ Zea mays $</ i>L$. $)$. J. Agric. Food Chem., 55: 9124-9127.

[5] Khare, C.P., 2007 Indian Medicinal Plants-an Illustrated Dictionary. Spinger Pvt. Ltd., India, pp: 732.

[6] Langseth, L., 2009. Antioxidants and their Effect on Health. In: Essentials of Functional Foods, Schmidl, M.K. and T.P. Labuza (Eds.). $1^{\text {st }}$ Edn. Aspen Publication, Maryland, pp: 303-318.

[7] Lans, C., 2006. Ethnomedicines used in trinidad and tobago for urinary problems and diabetes mellitus. J. Ethnobiol. Ethnomed., Vol. 2.

[8] Lil, Z.H. and Z. Yan, 2009. Research progress on pharmacological function of corn silk. J. Jilin Inst. Chem. Tech., 2: 1309-1315.

[9] Sharma, A.K., S.S. Purohit and N. Das Prajapati, 2009. A Handbook of Medicinal Plants: A Complete Source Book. Agrobios, india.

[10] Schmidl,M.K and Labuza,T.P,2009. Essentials of Functional foods.Aspen Publication, New York. Pp:258-264.

[11]Raj, D., R. Sharma and V.K. Joshi, 2011. Quality Characteristics. In: Quality Control for Value Addition in Food Processing, Devraj, R.S. and V.K. Joshi (Eds.). New Delhi Publishing Agency, India, pp: 57-68.

[12] Rosli, W., W.I. Nurhanan, A.R. Mohsin, S.S.J. Farid and C. Ghazali, 2008. Aqueous, alcoholic treatment and proximate analysis of $<\mathrm{i}>$ Maydis stigma $</ i>\quad(<i>$ Zea mays $</ i>$ Hairs). Ann. Microscopy, 8: 66-72. 